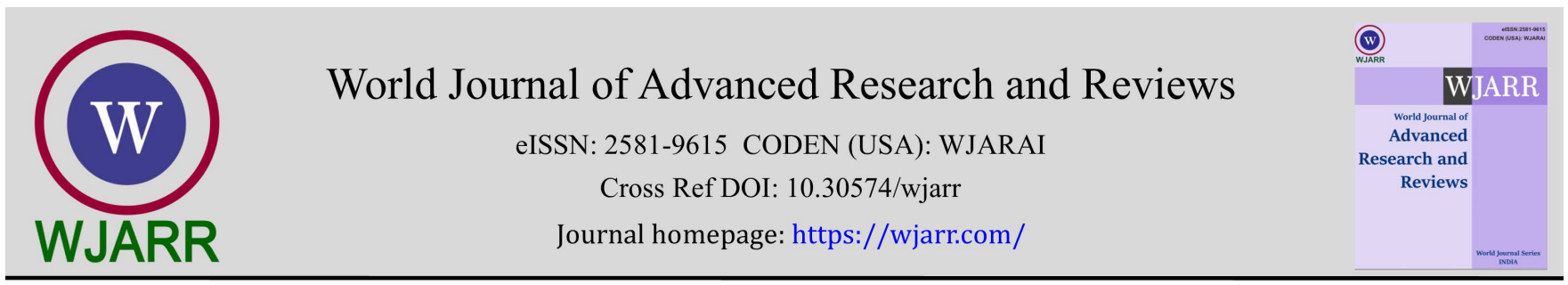

(RESEARCH ARTICLE)

\title{
Relationship between Fingerprint patterns and Multiple Intelligence among young adults in Nnamdi Azikiwe University, Anambra State
}

\author{
Nkemjika Grace Nnama * and Damian Ezejindu \\ Nnamdi Azikiwe University, Nnewi. \\ World Journal of Advanced Research and Reviews, 2021, 12(01), 349-354 \\ Publication history: Received on 12 September 2021; revised on 12 October 2021; accepted on 14 October 2021
}

Article DOI: https://doi.org/10.30574/wjarr.2021.12.1.0445

\begin{abstract}
The field of neuroscience is fast emerging with the various types of intelligence becoming critical to the overall wellbeing of an individual. The aim of this study is to understand the relationship between fingerprint patterns and multiple intelligence among young adults (18-26 years) in Nnamdi Azikiwe University, Anambra state. Two hundred and forty one subjects were enlisted in this study, comprising 140 females (58.1\%) and 101 males (41.9\%). Each subject filled the Howard Gardner model of Multiple intelligence test and were examined on the different forms of Multiple Intelligence: Linguistic, Logical, and Kinesthetic. Musical, Spatial, Interpersonal, Intrapersonal and Naturalist intelligences. Their fingerprint patterns were gotten with a fingerprint scanner. The data collected was analyzed using the IBM Statistical Package of Social Sciences (SPSS 2.0). Also Chi square test was used to test the differences between variable groups and analysis showed that intrapersonal intelligence had the highest percentage of $28.2 \%$ followed by logical and interpersonal intelligence. Naturalistic intelligence had the least percentage of 3.2\%. Males also showed a higher dominance of Logical, interpersonal, spatial, and kinesthetic intelligence; whereas females showed higher musical, naturalistic, linguistic, and intrapersonal intelligence. Also, the highest occurrence for the loop fingerprint was found among students with intrapersonal and musical intelligence; the highest occurrence for whorl was found among students with spatial and kinesthetic intelligence; and the highest occurrence of arch is found among students with naturalistic and linguistic intelligence. There was however, no significant difference observed in the relationship between multiple intelligence and tribe. The result of this study confirmed that every individual has different forms of intelligence at different levels and the knowledge of this may be useful in selecting career prospects.
\end{abstract}

Keywords: Fingerprint pattern; Multiple intelligence; Neurosciences; Intrapersonal intelligence; Career; Anambra State.

\section{Introduction}

Intelligence which is a complex psychological term is defined as "a very general mental capability that involves the ability to reason, plan, solve problems, think abstractly, comprehend complex ideas, learn quickly and learn from experience" [1]. The two figures most powerfully involved with the multiple intelligence world were Sternberg [2] and Gardner [3]. Howard Gardner [4] came up with eight forms of intelligences; verbal/linguistic, logic/mathematic, visual, kinesthetic, intrapersonal, interpersonal, musical and naturalistic intelligences. They are collectively referred to as multiple intelligence. An assessment of these forms of intelligence do not produce an IQ score but only serves to highlight an individual's strength across the various types of intelligence [3]. The development of the human brain which is the seat of all intelligence is related to that of the fingerprint [5]. Fingerprint patterns which are genetically determined [6] are impressions of patterns formed on the epidermal ridge on the finger tips [7]. The usefulness of fingerprints goes beyond the identification of individuals as research reveals the ability to identify unique potentials in individuals through fingerprint analysis [8]. Fingerprints patterns have also been linked to the diagnosis of various

\footnotetext{
*Corresponding author: Nkemjika Grace Nnama; E mail:nkemjikannama@gmail.com

Nnamdi Azikiwe University, Nnewi.

Copyright (C) 2021 Author(s) retain the copyright of this article. This article is published under the terms of the Creative Commons Attribution Liscense 4.0.
} 
medical, genetic and psychological condition [9]. Few studies have been carried out on the correlation between fingerprint patterns and multiple intelligence, one of which was carried out by Adekoya et al., [10] among secondary school students in Lagos, Nigeria and another by Durga [11] among students of Sharda University, India. To the best of our knowledge, no literature is available on such studies from Eastern, Nigeria. This present study is therefore aimed to study the relationship between fingerprint patterns and multiple intelligence among young adults in Nnamdi Azikiwe University, Anambra State, Nigeria.

\section{Material and methods}

\subsection{Study setting}

This descriptive cross sectional study was carried out in the Department of Human Anatomy, Nnamdi Azikiwe University, as part of the requirements for my Master's degree program.

\subsection{Study sampling}

A cross section of two hundred and forty one students were adopted for this study from Nnamdi Azikiwe University, Nigeria. The subjects comprised 140 females and 101 males within the age range of 18-26 years.

\subsection{Ethical approval}

Approval for the study was obtained from the Institutional Ethics Committee.

\subsection{Inclusion and exclusion criteria}

Subjects with deformity and inflammation on their fingers, no fingerprint (adermatoglyphia), with history of genetic diseases such as diabetes, schizophrenia and subjects outside the age range of 18 to 26 were exempted from this study.

\subsection{Evaluation of multiple intelligence}

Multiple Intelligence profile of the subjects was evaluated using questionnaires by Howard Gardner multiple intelligence- test. The questionnaire had 102 statements in total related to the nine intelligences he proposed. Each student was required to complete the questionnaire by placing Y(YES) or N (NO) to each statement which they felt accurately described them or not respectively. Students were assessed on each of the Multiple Intelligence type.

\subsection{Data collection}

The finger print patterns of students were scanned using the Digitalpersona fingerprint capture coupled with its automated fingerprint imaging software. The patterns were recorded and saved on a laptop for further analysis.

\subsection{Descriptive dermatoglyphics}

The fingerprints patterns were classified into Arch, Loop and Whorl.

Arch: The defining characteristics is the absence of delta. The ridges enter from one side of the finger and flow to the other end either forming a wave or an upthrust.

Loop: The ridges enter from either side of the finger, recurves and forms a delta and then terminates on the direction from which it entered.

Whorl: In this, there is a presence of two or more deltas and the formation of composites.

\subsection{Data analysis}

The first manual analysis was done to ascertain the preferred, un preferred and dominant forms of multiple intelligence which individual subjects possess. The data collected was analyzed using the IBM Statistical Package of Social Sciences (SPSS 2.0). Also Chi square test was used to test the differences between variable groups, and values were considered significant at $\mathrm{p}$ less than 0.05 . 


\subsection{Grading of multiple intelligence}

The grading was done in accordance to the Howard Gardener model of grading as found in the third page of the questionnaire the total number of Y (YES) and N (NO) on each column was gotten. The number of N (NO) was subtracted from the number of Y (YES) and a relative score was arrived at.

\section{Results}

The result of the multiple intelligence test revealed that intrapersonal intelligence had the highest percentage of $28.2 \%$ followed by logical intelligence $(19.9 \%)$ and interpersonal intelligence $(15.0 \%)$. Naturalistic intelligence had the least percentage of $3.2 \%$.

Table 1 Distribution of dominant multiple intelligence among study participants

\begin{tabular}{|l|c|c|}
\hline Multiple intelligence & $\mathbf{N}$ & Percent \\
\hline Logical & 81 & $19.9 \%$ \\
\hline Musical & 44 & $10.8 \%$ \\
\hline Interpersonal & 61 & $15.0 \%$ \\
\hline Naturalistic & 13 & $3.2 \%$ \\
\hline Spatial & 34 & $8.3 \%$ \\
\hline Linguistic & 35 & $8.6 \%$ \\
\hline Intrapersonal & 115 & $28.2 \%$ \\
\hline Kinesthetic & 25 & $6.1 \%$ \\
\hline Total & 408 & $100 \%$ \\
\hline
\end{tabular}

The distribution of dominant multiple intelligence among gender (male and female) showed a higher dominance of Logical, Interpersonal, Spatial and Kinesthetic intelligence in males whereas females showed higher Musical, Naturalistic, Linguistic and Intrapersonal intelligences.

Table 2 Distribution of dominant multiple intelligence among gender

\begin{tabular}{|c|c|c|c|c|}
\hline & & \multicolumn{2}{|c|}{ Gender } & \multirow[b]{2}{*}{$\mathrm{X}^{2}$} \\
\hline & & Female & Male & \\
\hline & & Count & Count & \multirow{8}{*}{$0.000^{*}$} \\
\hline \multirow[t]{8}{*}{ Multiple Intelligence } & Logical & 47 & 34 & \\
\hline & Musical & 31 & 13 & \\
\hline & Interpersonal & 33 & 28 & \\
\hline & Naturalistic & 8 & 5 & \\
\hline & Spatial & 15 & 19 & \\
\hline & Linguistic & 23 & 12 & \\
\hline & Intrapersonal & 80 & 35 & \\
\hline & Kinesthetic & 6 & 19 & \\
\hline
\end{tabular}


The highest occurrence for the loop fingerprint was found among students with intrapersonal and musical intelligence; the highest occurrence for whorl was found among students with spatial and kinesthetic intelligence; and the highest occurrence of arch is found among students with naturalistic and linguistic intelligence.

Table 3 Distribution of fingerprint patterns across students exhibiting various dominant multiple intelligence

\begin{tabular}{|l|l|l|l|l|}
\hline & Whorl & Loop & Arch & $\mathbf{X}^{2}$ \\
\hline Logical & $32.1 \%$ & $53.1 \%$ & $14.8 \%$ & \\
\cline { 1 - 4 } Musical & $22.7 \%$ & $70.5 \%$ & $6.8 \%$ & \\
Interpersonal & $26.2 \%$ & $65.6 \%$ & $8.2 \%$ & \multirow{2}{*}{0.001} \\
\hline Naturalistic & $30.8 \%$ & $46.2 \%$ & $23.1 \%$ & \multirow{2}{*}{} \\
\cline { 1 - 4 } Spatial & $44.1 \%$ & $50.0 \%$ & $5.9 \%$ & \\
\hline Linguistic & $28.6 \%$ & $51.4 \%$ & $20.0 \%$ & \\
\cline { 1 - 3 } Intrapersonal & $18.3 \%$ & $71.3 \%$ & $10.4 \%$ & \\
\hline Kinesthetic & $40.0 \%$ & $48.0 \%$ & $12.0 \%$ & \\
\hline
\end{tabular}

No significant difference was observed in the various forms of multiple intelligence among all three regions $(p=0.226)$. Note: Values are considered significant at $\mathrm{p}<0.05$.

Table 4 Distribution of multiple intelligence among region

\begin{tabular}{|c|c|c|c|c|c|}
\hline & & \multicolumn{2}{|l|}{ TRIBE } & \multirow{3}{*}{$\mathrm{X}^{2}$} \\
\hline & & \multirow{3}{*}{$\begin{array}{c}\text { South East } \\
\text { Count } \\
\end{array}$} & South South & South West & \\
\hline & & & & & \\
\hline & & & Count & Count & \\
\hline \multirow[t]{8}{*}{ MI } & Logical & 73 & 5 & 3 & \multirow{7}{*}{0.226} \\
\hline & Musical & 41 & 3 & 0 & \\
\hline & Interpersonal & 58 & 1 & 2 & \\
\hline & Naturalistic & 13 & 0 & 0 & \\
\hline & Spatial & 32 & 1 & 1 & \\
\hline & Linguistic & 30 & 5 & 0 & \\
\hline & Intrapersonal & 106 & 7 & 2 & \\
\hline & Kinesthetic & 23 & 1 & 1 & \\
\hline
\end{tabular}

No statistical difference was observed in the distribution of fingerprint patterns across different regions $(\mathrm{P}=0.589)$.

Table 5: Distribution of fingerprint patterns across regions

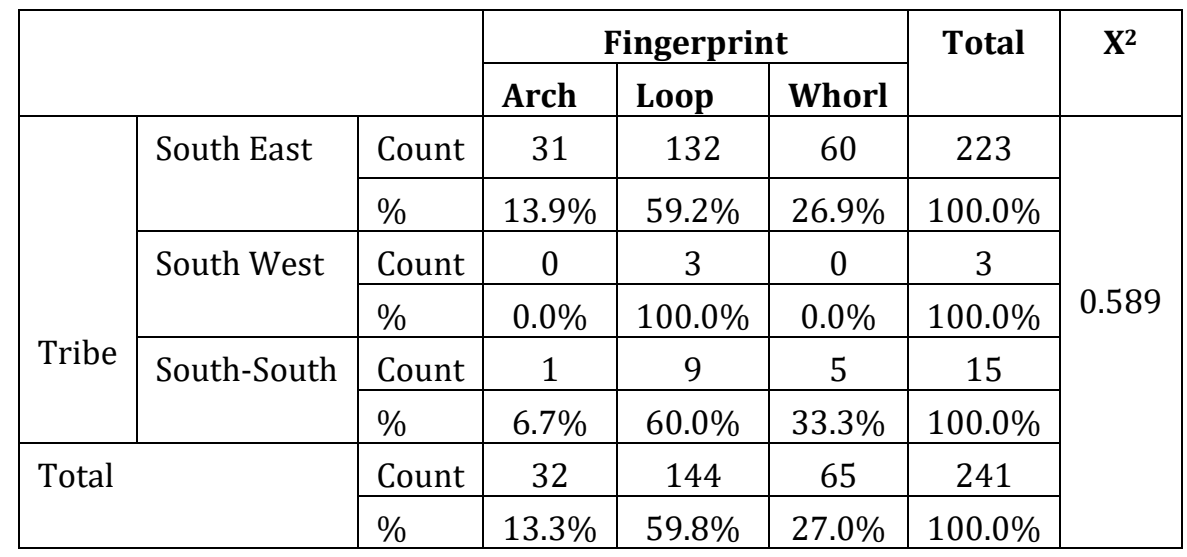




\section{Discussion}

In this study, intrapersonal intelligence has the highest percentage of $28.2 \%$ followed by logical intelligence and interpersonal intelligence. This study is similar to Adekoya et al., [10] who also recorded that intrapersonal intelligence has the highest mean score of 76.31 \pm 15.43 followed by interpersonal intelligence and visual intelligence. A study carried out by Durga [11] also reported intrapersonal intelligence to be consistently high across students of all courses. Intrapersonal intelligence also known as metacognitive skill entails self- knowledge, self-regulation, self-control and executive functions [12]. The reason for high scores in intrapersonal intelligence (being aware of one's emotions) may be as a result of the fact that the study was carried out on university students and they are believed to be matured enough and more capable of identifying their inherent strength and weaknesses [11]. Naturalistic intelligence had the least percentage in this study.

It was also observed that males have higher dominance in logical intelligence, interpersonal intelligence, spatial intelligence and kinesthetic intelligence while females have higher dominance in musical intelligence, naturalist intelligence, linguistic intelligence and intrapersonal intelligence. A study carried out on the multiple intelligence levels of secondary school students also documented that males were good at spatial intelligence which is one form of intelligence the males have high dominance in from this present study [13]. There is however a slightly close similarity with this work and that of Adekoya et al., [10] who recorded that males have higher verbal, logic, natural, intrapersonal and kinesthetic intelligences while females have higher interpersonal, musical and visual intelligences. The similarity here is in the fact that in both studies, males are shown to have higher dominance in logical and kinesthetic intelligence while females have higher dominance in musical intelligence. There is also a marked difference in the counts between male (28) and female (33) in interpersonal intelligence. This is similar to the works of Adekoya et al., [10] and Nanakorn [14]. This suggests early reproductive maturity in female than their male counterparts which as opined by Lynn and Kanazawa [15] is a natural phenomenon that tends to make females more aware of their environment earlier than their male counterparts.

It was also observed that there is a significant difference in the pattern of fingerprint distribution in each dominant multiple intelligence group. The highest occurrence for the loop fingerprint was found among students with intrapersonal and musical intelligence; the highest occurrence for whorl was found among students with spatial and kinesthetic intelligence; and the highest occurrence of arch is found among students with naturalistic and linguistic intelligence. The result of this present study is quite different from those reported in previous studies but has a little similarity with a study conducted by Durga et al., [11] where he documented that a higher frequency of loop was observed in students with kinesthetic intelligence, whorl in students with logical intelligence and arch with students with linguistic intelligence. The similarity here is in the relationship between arch fingerprint pattern and linguistic intelligence. According to Adekoya et al., [10] ulnar loop pattern on the second digit of both right and left hands could indicate high logic intelligence while high frequency of arch especially on the index finger could indicate high musical intelligence. Yohannes \& Bekele [16] reported that loop and whorl are associated with linguistic intelligence whereas spatial intelligence is associated with arch. The differences observed in these results could be as a result of racial differences [16].

There is no statistical difference in the distribution of fingerprint patterns among different regions (South East, South South, and South West). This is as a result of the fact that the research was conducted in an area densely populated by the Igbos hence the data gotten for the fingerprint pattern of other regions were insignificant.

\section{Limitation}

The limitations experienced in the course of this work were small sample size and poor distribution of diverse tribes across sampling population. The study was carried out in an area densely populated by the Igbos so associating tribe to other variables was almost impossible as the Igbos (South East) took the higher percentage as against the South West and South South. More studies on the relationship between fingerprint patterns and multiple intelligences with larger sample size comprising different people of different tribes should be carried out to unravel different association that could exist between these parameters.

\section{Conclusion}

This study reveals that intrapersonal intelligence is predominant among the study population and that the highest occurrence for the loop fingerprint is among students with intrapersonal and musical intelligence; the highest occurrence for whorl is among students with spatial and kinesthetic intelligence; and the highest occurrence of arch is among students with naturalistic and linguistic intelligence. This study also confirms that every individual has different 
profile of Multiple Intelligence and the knowledge of this may be beneficial for career selection by matching the Multiple Intelligence profile with available career option.

\section{Compliance with ethical standards}

\section{Acknowledgments}

The authors acknowledge the students of Nnamdi Azikiwe University, Anambra State who partook in this research for their cooperation.

\section{Statement of informed consent}

Informed consent was obtained from all individual participants included in the study.

\section{References}

[1] Gottfredson LS. Why g matters. The complexity of everyday life. Intelligence. 1997; 24(1): 79-132.

[2] Sternberg RJ. Toward a triarchic theory of human intelligence. Behavioral and Brain Sciences. 1984; 7(2): 269316.

[3] Gardner H. Frames of mind; the theory of multiple intelligences. 1st Edition. New York. Basic Books. 1983.

[4] Gardner H. Intelligence Reframes: Multiple intelligences for the 21st century. 1999.

[5] Kumari D, Vijaya Babu D, Kumar D. Dermatoglyphics and Its Relation to Intelligence Levels of Young Students. IOSRJDMS. 2014; 13(5): 01-03.

[6] Gutierez SB, Lucenario JLS, Yebes MJT. Dermatoglyphic studies among the Dumagat-Remontado tribal population of the Philippines. Journal of Anthropology. 2012.

[7] Cummins H. Epidermal ridge configuration in developmental defects impact reference to ontogenetic factors which condition ridge direction. Am J of Anatomy? 1926; 38-89.

[8] Raizada A. A Cross-Sectional Study on the Palmar Dermatoglyphics in Relation to Carcinoma Breast Patients. JCDR. 2013.

[9] Weinstein DD, Schiffman J, Walker E, Bonsall R. Minor physical anomalies, dermatoglyphics asymmetries and cortisol levels in adolescents with schizotypal personality disorder. Am. J. Psy. 1999; 156(4): 617-23.

[10] Adekoya K, Oboh B, Alimba CG. Relationships between dermatoglyphics and Multiple Intelligence among selected Secondary School students in Lagos State. NISEB Journal. 2013; 13(3).

[11] Durga P, Poonam K, Prajna PS. Identification and Correlation of the Multiple Intelligences and Fingerprint Patterns. Int. J of Anatomy, Radiology and Surgery. 2017; 6(2).

[12] Shearer CB, Karanian JM. The neuroscience of intelligence: Empirical support for the theory of multiple intelligences. Trends Neurosci. Educ. 2017; 6: 211-223.

[13] Anitha TS, Vanessa J, Sreelakshmi G. A study on the multiple intelligence levels of secondary school students in Government schools and private schools. IOSR Journals. 2013; 3(4); 12-18.

[14] Nanakorn S, Honark N, Ungpansattawong S, Chaisiwamongkol W, Maneesriwongul W, Suwanwerakamtorn R, Raksasataya S, Chusilp K. Fingerprint Pattern and Multiple Intelligence: a Preliminary Study. KKU Science Journal. 2011; 39(1): 105-112.

[15] Lynn R, Kanazawa S. A longitudinal study of sex differences in intelligence at ages 7,11 and 16 years. Personality and Individual Differences. 2011; 51: 321-324.

[16] Yohannes S, Bekele E. Ethopian population Dermatoglyphic study reveals linguistic straitification of diversity. PLoSOne. 2015; 10(6). 